\title{
Acute protection against exercise-induced bronchoconstriction by formoterol, salmeterol and terbutaline
}

\author{
K. Richter, S. Janicki, R.A. Jörres, H. Magnussen
}

Acute protection against exercise-induced bronchoconstriction by formoterol, salmeterol and terbutaline. K. Richter, S. Janicki, R.A. Jörres, H. Magnussen. (C)ERS Journals Ltd 2002.

ABSTRACT: The onset of bronchoprotection as obtained by various $\beta_{2}$-agonists has not been examined in a comparitive study. In this study, the onset of bronchodilation and protection against exercise-induced bronchoconstriction in asthmatics after inhalation of the long-acting $\beta_{2}$-agonists formoterol and salmeterol and the shortacting $\beta_{2}$-agonist terbutaline were measured.

Twenty-five subjects with asthma and a history of exercise-induced bronchoconstriction (mean baseline forced expiratory volume in one second (FEV1): 90\% predicted; mean fall in FEV1 after exercise: 31\% from baseline) were enrolled in this double-blind, double-dummy, placebo-controlled, randomized, four-period crossover study. Exercise challenges were performed on 12 days at either 5, 30, or 60 min after inhalation of

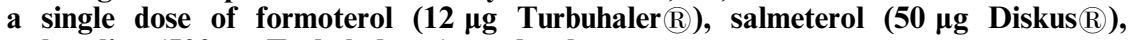
terbutaline $(500 \mu \mathrm{g}$ Turbuhaler $\AA)$ or placebo.

Exercise-induced bronchoconstriction (maximum fall in FEV1 or area under the curve) did not differ significantly between terbutaline, formorerol and salmeterol either 5, 30, or $60 \mathrm{~min}$ after inhalation of the study medication. In contrast, the onset of bronchodilation was slower after salmeterol compared to terbutaline and formoterol $(p<0.05$, each), which both showed a similar time course. At all time points between 5 and $60 \mathrm{~min}$, formoterol provided significantly greater bronchodilation than salmeterol $(\mathbf{p}<\mathbf{0 . 0 5})$.

These data indicate that equipotent doses of the bronchodilators salmeterol, formoterol and terbutaline were similarly effective with respect to their short-term protective potency against exercise-induced bronchoconstriction, despite the fact that the time course of bronchodilation was significantly different between the three $\boldsymbol{\beta}_{\mathbf{2}}$-agonists. Eur Respir J 2002; 19: 865-871.
Pulmonary Research Institute, Hospital Großhansdorf, Centre for Pneumology and Thoracic Surgery, Großhansdorf, Germany.

Correspondence: H. Magnussen

Hospital Großhansdorf

Centre for Pneumology and Thoracic Surgery

Wöhrendamm 80

D-22927 Großhansdorf

Germany

Fax: 494102601245

E-mail: magnussen@pulmoresearch.de

Keywords: Exercise-induced asthma formoterol

protection

salmeterol

terbutaline

Received: March 222001

Accepted after revision November 23 2001

This study was supported by Astra GmbH, Wedel, Germany.
Current guidelines for the treatment of asthma recommend short-acting $\beta_{2}$-adrenoceptor agonists for symptom relief and long-acting $\beta_{2}$-agonists for control $[1,2]$. Among the long-acting compounds, salmeterol and formoterol are known to have a similar duration of action in terms of bronchodilation and protection against methacholine [3] or exercise-induced bronchoconstriction [4-6]. Both compounds, however, have a different onset of action with regard to bronchodilation [7] and smooth muscle relaxation [8].

The onset of action is of special interest in view of the fact that effective treatment of asthma includes both rapid bronchodilation and protection against bronchoconstrictor stimuli. As these two end-points are not necessarily linked to each other [9], the assumption that they have an identical time course cannot be made. Previous studies have assessed the protection against exercise-induced bronchoconstriction, either $2 \mathrm{~h}$ after inhalation $[5,6]$ or later $[10]$ in the case of formoterol, or $30 \mathrm{~min}$ [11] to $1 \mathrm{~h}$ [12] after inhalation or later in the case of salmeterol. Given that bronchodilator data indicate that the difference between the drugs is most pronounced early after inhalation, it seems important to establish the initial time course of protection by these drugs under comparable conditions.

Therefore in this study, the onset of protection against exercise-induced bronchoconstriction 5, 30 and $60 \mathrm{~min}$ after inhalation of equipotent doses of formoterol and salmeterol, the short-acting $\beta_{2}$-agonist terbutaline, and placebo using identical exercise protocols in the same patients were measured.

\section{Methods}

\section{Subjects}

Twenty-five nonsmoking patients (15 male/10 female; mean age: $33 \mathrm{yrs}$; table 1) completed the study. One patient was excluded after visit two due to a deterioration in forced expiratory volume in one second (FEV1) to $<60 \%$ predicted. All patients had mild to moderate asthma according to international guidelines [2], FEV1 $\geqslant 60 \%$ pred, a history of exercise-induced bronchoconstriction and documented hyperresponsiveness to inhaled methacholine (provocative concentration causing a $20 \%$ fall in FEV $\left.1 \leqslant 8 \mathrm{mg} \cdot \mathrm{mL}^{-1}\right) ; 24$ of them also showed a positive 
Table 1. - Subjects characteristics

\begin{tabular}{|c|c|c|c|c|c|c|c|c|c|c|c|c|}
\hline $\begin{array}{l}\text { Subject } \\
\mathrm{n}\end{array}$ & $\begin{array}{l}\text { Sex } \\
\mathrm{m} / \mathrm{f}\end{array}$ & $\begin{array}{l}\text { Age } \\
\text { yrs }\end{array}$ & $\begin{array}{l}\text { Height } \\
\mathrm{cm}\end{array}$ & $\begin{array}{c}\text { Weight } \\
\mathrm{kg}\end{array}$ & $\begin{array}{c}\text { Allergy } \\
+/-\end{array}$ & $\begin{array}{l}\text { Total IgE } \\
\text { IgE } \cdot \mathrm{mL}^{-1}\end{array}$ & $\begin{array}{c}\mathrm{PC} 20 \mathrm{FEV} 1 \\
\mathrm{mg} \cdot \mathrm{mL}^{-1} \cdot \mathrm{Mch}^{-1}\end{array}$ & $\underset{\%=\uparrow}{\Delta \mathrm{FEV} 1}$ & $\begin{array}{l}\mathrm{VC} \\
\mathrm{L}\end{array}$ & $\begin{array}{l}\text { FEV1 } \\
\% \text { opred }\end{array}$ & $\underset{\%}{\mathrm{FEV}_{1} / \mathrm{VC}}$ & Treatment \\
\hline 1 & $\mathrm{~m}$ & 36 & 172 & 71 & + & 39 & 0.10 & -15.9 & 4.92 & 96.1 & 75.4 & $\beta_{2}$ \\
\hline 2 & $\mathrm{~m}$ & 29 & 182 & 98 & + & 172 & 0.09 & -21.7 & 4.83 & 73.9 & 68.7 & $\beta_{2}$ \\
\hline 3 & $\mathrm{f}$ & 32 & 165 & 65 & + & 710 & 0.06 & -27.5 & 3.39 & 97.8 & 90.0 & \\
\hline 4 & $\mathrm{~m}$ & 31 & 185 & 69 & + & 287 & 0.14 & -22.1 & 5.30 & 100.9 & 87.0 & $\beta_{2}$ \\
\hline 5 & $\mathrm{~m}$ & 35 & 168 & 68 & + & 23 & 0.19 & -24.0 & 4.45 & 70.7 & 59.1 & $\beta_{2} \mathrm{FLU}$ \\
\hline 6 & f & 47 & 170 & 61 & + & 105 & 0.04 & -54.4 & 4.08 & 80.6 & 58.1 & $\beta_{2}$ \\
\hline 7 & $\mathrm{f}$ & 25 & 170 & 60 & + & 522 & 0.04 & -31.0 & 4.67 & 105.4 & 78.8 & $\beta_{2}$ BUD \\
\hline 8 & $\mathrm{~m}$ & 28 & 190 & 102 & + & 478 & 0.12 & -30.5 & 6.15 & 107.0 & 84.7 & $\beta_{2} \mathrm{FLU}$ \\
\hline 9 & $\mathrm{f}$ & 43 & 181 & 85 & + & 39 & 0.04 & -16.8 & 4.20 & 82.4 & 68.1 & $\beta_{2} \mathrm{FLU}$ \\
\hline 10 & $\mathrm{f}$ & 27 & 175 & 75 & + & 170 & 0.15 & -46.2 & 4.18 & 94.8 & 82.5 & $\beta_{2} \mathrm{BDP}$ \\
\hline 11 & $\mathrm{~m}$ & 32 & 181 & 77 & + & 344 & 0.26 & -22.8 & 5.53 & 91.7 & 72.3 & $\beta_{2}$ \\
\hline 12 & $\mathrm{~m}$ & 34 & 185 & 80 & + & 82 & 0.33 & -27.9 & 5.99 & 104.0 & 77.8 & $\beta_{2}$ \\
\hline 13 & $\mathrm{~m}$ & 34 & 176 & 72 & + & 340 & 0.10 & -24.6 & 5.58 & 95.4 & 69.9 & $\beta_{2}$ BUD \\
\hline 14 & $\mathrm{~m}$ & 27 & 187 & 87 & + & 843 & 0.08 & -22.7 & 6.11 & 85.1 & 66.4 & $\beta_{2}$ \\
\hline 15 & $\mathrm{~m}$ & 26 & 193 & 98 & + & 165 & 0.09 & -28.0 & 7.64 & 113.9 & 75.3 & $\beta_{2}$ \\
\hline 16 & $\mathrm{~m}$ & 35 & 186 & 76 & + & 284 & 0.78 & -46.6 & 5.47 & 90.9 & 74.6 & $\beta_{2} \mathrm{BDP}$ \\
\hline 17 & $\mathrm{~m}$ & 36 & 191 & 72 & + & 72 & 0.13 & -39.8 & 6.31 & 82.1 & 60.9 & $\beta_{2} \mathrm{BDP}$ \\
\hline 18 & $\mathrm{~m}$ & 25 & 176 & 72 & + & 735 & 0.12 & -38.2 & 4.38 & 70.3 & 69.9 & $\beta_{2}$ \\
\hline 19 & $\mathrm{f}$ & 30 & 165 & 57 & + & 1908 & 0.12 & -25.1 & 3.46 & 91.8 & 84.1 & $\beta_{2} \mathrm{BDP}$ \\
\hline 20 & $\mathrm{~m}$ & 30 & 186 & 81 & + & 178 & 0.20 & -21.7 & 5.07 & 89.2 & 81.7 & $\beta_{2}$ \\
\hline 21 & $\mathrm{f}$ & 48 & 168 & 78 & + & 63 & 0.26 & -45.7 & 3.86 & 81.0 & 59.6 & $\beta_{2}$ \\
\hline 22 & $\mathrm{~m}$ & 32 & 183 & 68 & + & 184 & 0.29 & -48.0 & 5.75 & 102.0 & 79.0 & $\beta_{2}$ \\
\hline 23 & $\mathrm{f}$ & 37 & 176 & 119 & + & 499 & 0.07 & -49.0 & 3.77 & 76.7 & 69.8 & $\beta_{2} \mathrm{BUD}$ \\
\hline 24 & $\mathrm{f}$ & 30 & 158 & 49 & - & 30 & 0.16 & -29.2 & 3.42 & 94.8 & 80.1 & $\beta_{2}$ BUD \\
\hline 25 & $\mathrm{f}$ & 36 & 168 & 60 & + & 77 & 0.03 & -16.3 & 3.13 & 79.3 & 79.6 & $\beta_{2}$ \\
\hline Mean & & 33.0 & 177.5 & 76.0 & & 334 & 0.12 & -31.0 & 4.87 & 90.3 & 74.1 & \\
\hline SD & & 6.1 & 9.4 & 15.7 & & 405 & $2.16^{+}$ & 11.5 & 1.12 & 11.8 & 9.0 & \\
\hline
\end{tabular}

IgE: immunoglobulin-E; FEV1: forced expiratory volume in one second; PC20: provocative concentration causing a $20 \%$ fall in FEV1; Mch: metacholine; VC: vital capacity; m: male; f: female; $\beta_{2}$ : $\beta$-agonist as needed; FLU: fluticasone; BUD: budesonide; BDP: beclomethasone. ${ }^{\#}$ : skin-prick test with a positive response against $\geqslant 20$ common allergens; ${ }^{\uparrow}$ : fall in FEVi after exercise at screening ( $\%$ of baseline); ${ }^{+}$: geometric mean (SD expressed as a factor).

skin prick to at least one of 20 common allergen extracts. None of the patients had had a respiratory tract infection during the 4-weeks preceding each of the study visits. Furthermore, their current asthma medication was unchanged for the 6-weeks prior to entry into the study and throughout the study. Antihistamines, anticholinergics, inhaled cromoglycates and prednisolone were not permitted at all. Eleven patients were treated with inhaled corticosteroids. The study was approved by the local Ethics Committee and all subjects gave their written informed consent.

\section{Study design}

The study was performed using a double-blind, double-dummy, placebo-controlled, randomized, fourperiod crossover design involving 13 visits. On visit one (screening) the history of exercise-induced bronchoconstriction was confirmed by an exercise challenge. On the remaining 12 visits, which were separated by $\geqslant 48 \mathrm{~h}$, patients attended the hospital at approximately the same time of the day $(09.00 \pm 1 \mathrm{~h})$ to avoid the influence of circadian rhythm. After measuring baseline FEV1, the study medication was inhaled. The dose of $500 \mu \mathrm{g}$ terbutaline was given by Turbuhaler $\AA$ (AstraZeneca, Lund, Sweden), $12 \mu \mathrm{g}$ formoterol given by Turbuhaler $\mathbb{R}$ and $50 \mu \mathrm{g}$ salmeterol given by Diskus $\mathbb{R}$ (GlaxoSmithKline, Uxbridge,
UK). Placebo Turbuhalers $\AA$ and placebo Diskus $\AA$ were also used. On each treatment visit, patients

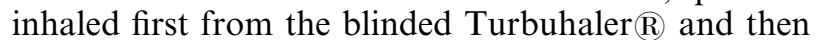

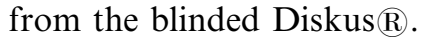

The exercise challenge started 5,30 or 60 min later. On the day of the 5-min challenge, the FEV1 was determined just before and this value also served as the pre-exercise value. On the day of the 30-min challenge, the FEV1 was measured 5, 15 and 30 min after inhalation, and at the $60 \mathrm{~min}$ challenge at 5,15 , 30 and $60 \mathrm{~min}$ after inhalation, the 30 and $60 \mathrm{~min}$ values were taken as the respective pre-exercise values.

\section{Spirometry}

Spirometry was performed using an electronic spirometer (Masterscope V4.1; Jaeger, Hoechberg, Germany) following international guidelines [13]. All manoeuvres were performed in triplicate, and the best value recorded. To achieve comparable baseline values, the deviation of FEV1 from the screening value had to be $<10 \%$ at each treatment visit.

\section{Exercise challenges}

On all test days patients were asked to refrain from vigorous exercise. If outdoor temperatures were 
$<0^{\circ} \mathrm{C}$, they had to stay in the clinic for $\geqslant 60 \mathrm{~min}$ before inhalation of the study medication.

Exercise challenges were performed only if FEV1 was $>60 \%$ pred. To reduce the variability of responses, the temperature $\left(-12^{\circ} \mathrm{C}\right)$ and relative humidity (water content $<4 \mathrm{mg} \cdot \mathrm{L}^{-1}$ ) of inhaled air were kept constant. Cooling was achieved with a commercial heat exchanger (Respiratory Heat Exchanger System; Jaeger, Hoechberg, Germany). The exhaled air was conducted through a heated pneumotachograph and ventilation rates were calculated. Exercise challenges were performed on a cycle ergometer (Draeger, Lübeck, Germany) for a total of $6 \mathrm{~min}$. On the screening visit the workload was increased in a stepwise manner until $85 \%$ of the subject's predicted value of maximal heart rate was reached. This workload was chosen for all subsequent treatment visits. Spirometry was performed immediately before and 3 , $10,15,30,45,60$ and $90 \mathrm{~min}$ after the end of exercise.

\section{Data analysis}

Bronchodilation, expressed as per cent increase of FEV1 compared to baseline, was evaluated for the three different time intervals (5, 30 and $60 \mathrm{~min}$ ) between inhalation of the study medication and start of exercise.

Exercise-induced bronchoconstriction was quantified as maximum per cent fall in FEV1 compared to the pre-exercise value. In addition, the area under the curve of the per cent change in FEV1 from the end of exercise until $90 \mathrm{~min}$ (AUC 0-90 min) was determined.

To check for differences in baseline FEV1 before inhalation, values between the treatment periods and/or time points were compared using repeatedmeasures analysis of variance (ANOVA). The same approach was followed with pre-exercise FEV1 and ventilation rates during exercise. Bronchodilation was also compared between treatments by repeatedmeasures ANOVA. The analysis was performed separately for each of the three time intervals and these results are indicated in figure 1 . The per cent fall in FEV1 after exercise was analysed in the same manner. Pairwise comparisons between treatments regarding bronchodilation and bronchoprotection were performed by the paired t-test using a Bonferroni correction for 3 comparisons at each time point (figure 1). Statistical significance was assumed for $\mathrm{p}<0.05$. Since a preliminary analysis did not show sequence or period effects, these factors were discarded from further analysis.

\section{Results}

\section{Baseline measurements}

The mean \pm SEM values of baseline FEV1 before inhalation of the study medication were not significantly different on each study day (table 2). The mean ventilation rate after exercise at screening was $52.6 \mathrm{~L} \cdot \mathrm{min}^{-1}$. After exercise at 5,30 and $60 \mathrm{~min}$ after inhalation of the study medication it was 54.4, 56.0 and $55.3 \mathrm{~L} \cdot \mathrm{min}^{-1}$ for placebo, 54.0, 54.3 and $54.0 \mathrm{~L} \cdot \mathrm{min}^{-1}$ for terbutaline, 55.8, 57.0 and $55.8 \mathrm{~L} \cdot \mathrm{min}^{-1}$ for formoterol, and $55.9,57.6$ and $54.1 \mathrm{~L} \cdot \mathrm{min}^{-1}$ for salmeterol. There were no significant differences between values obtained at different time intervals or treatments.

\section{Bronchodilation}

Figure 1 shows the bronchodilation produced by each treatment, expressed as mean \pm SEM per cent changes of FEV1 at 5, 15, 30 and $60 \mathrm{~min}$. ANOVA revealed significant differences between the four treatment regimens at all time points $(p<0.001)$. At $5 \mathrm{~min}$, terbutaline produced a significantly stronger response than salmeterol $(\mathrm{p}<0.01$, each) and formoterol provided greater bronchodilation than salmeterol $(\mathrm{p}<0.05$, each) 5, 15, 30 and $60 \mathrm{~min}$ after
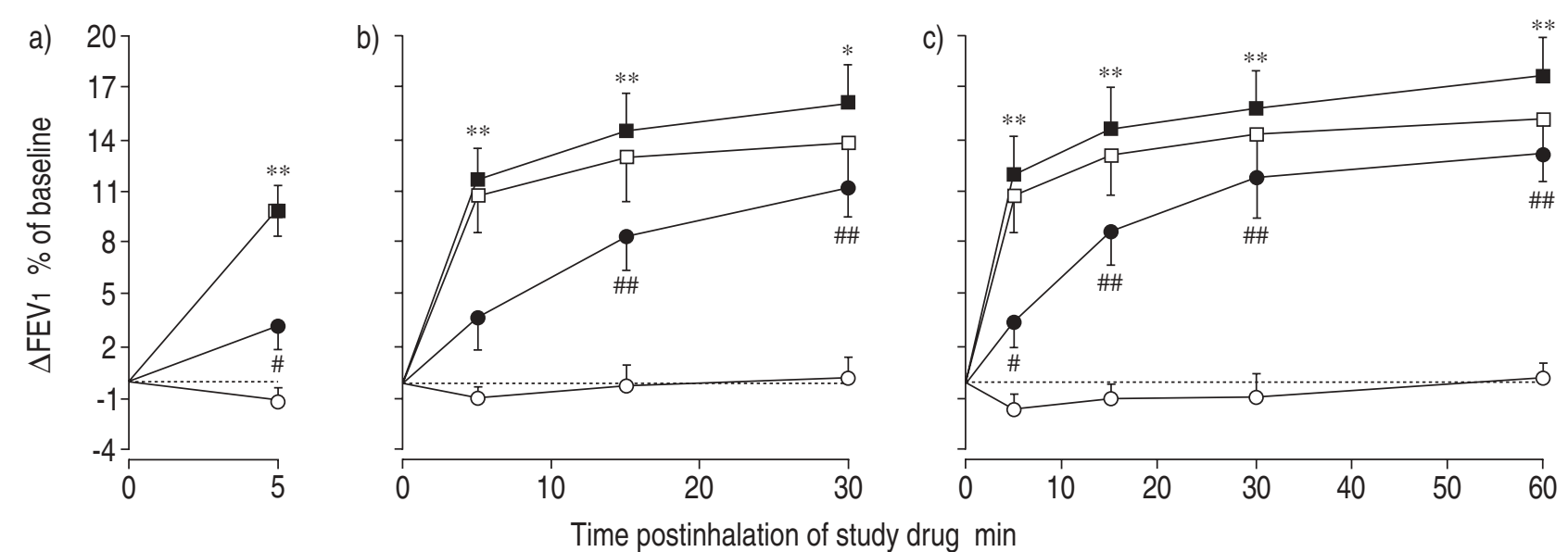

Fig. 1.-Bronchodilation expressed as forced expiratory volume in one second (FEV1) \% baseline for time intervals of a) 5 min, b) 30 min and c) 60 min between inhalation of the study drug and start of exercise. Data are expressed as mean \pm SEM. $\mathbf{\square}$ : formoterol; $\square$ : terbutaline; - : salmeterol; $\bigcirc$ : placebo. *: $\mathrm{p}<0.05$ formoterol versus salmeterol; **: $\mathrm{p}<0.01$ formoterol versus salmeterol; $\#$ : $\mathrm{p}<0.05$ salmeterol versus placebo; ${ }^{\# \#}: \mathrm{p}<0.01$ salmeterol versus placebo. 
Table 2. - Values of baseline and pre-exercise forced expiratory volume in one second for the three time intervals between inhalation of the study drug and the start of exercise

\begin{tabular}{|c|c|c|c|c|c|c|}
\hline \multirow[t]{2}{*}{ Study medication } & \multicolumn{2}{|c|}{5 min time interval } & \multicolumn{2}{|c|}{30 min time interval } & \multicolumn{2}{|c|}{60 min time interval } \\
\hline & baseline & pre-exercise & baseline & pre-exercise & baseline & pre-exercise \\
\hline Placebo & $3.57 \pm 0.19$ & $3.54 \pm 0.19$ & $3.59 \pm 0.19$ & $3.58 \pm 0.17$ & $3.57 \pm 0.16$ & $3.58 \pm 0.16$ \\
\hline Terbutaline & $3.58 \pm 0.20$ & $3.90 \pm 0.18$ & $3.63 \pm 0.18$ & $4.06 \pm 0.18$ & $3.57 \pm 0.18$ & $4.04 \pm 0.18$ \\
\hline Formoterol & $3.56 \pm 0.17$ & $3.90 \pm 0.17$ & $3.59 \pm 0.18$ & $4.07 \pm 0.18$ & $3.57 \pm 0.17$ & $4.14 \pm 0.18$ \\
\hline Salmeterol & $3.59 \pm 0.17$ & $3.68 \pm 0.17$ & $3.58 \pm 0.19$ & $3.93 \pm 0.18$ & $3.50 \pm 0.18$ & $3.88 \pm 0.17$ \\
\hline
\end{tabular}

Data are presented as mean \pm SEM.

inhalation. In contrast, terbutaline and formoterol did not show significantly different effects at any of the time points.

As a consequence of bronchodilation, mean preexercise FEV1 was significantly larger after terbutaline and formoterol compared to salmeterol and placebo in the tests involving a 5-min time interval between inhalation and exercise $(p<0.05$, each; table 2). In the tests involving the $30-\mathrm{min}$ or $60-\mathrm{min}$ time intervals, mean pre-exercise FEV1 was significantly larger after terbutaline, formoterol and salmeterol than after placebo $(p<0.01$, each; table 2$)$.

\section{Protection against exercise-induced bronchoconstriction}

When patients had inhaled placebo, the maximum decrease in FEV1 as well as the AUC was not significantly different between the three time intervals of 5, 30 and $60 \mathrm{~min}$ (table 3). The protective effects of terbutaline, formoterol and salmeterol, when administered 5, 30 and $60 \mathrm{~min}$ before the exercise challenge compared to placebo, are illustrated in figure 2. ANOVA showed significant differences between placebo, terbutaline, formoterol and salmeterol at all time points $(\mathrm{p}<0.001$, each), with the exception of 90-min postexercise when exercise had been started 30 -min after inhalation of the study medication. The maximum per cent as well as absolute fall in FEV1 after exercise did not differ significantly between terbutaline, formoterol and salmeterol for any of the three intervals between inhalation and exercise (taking into account the Bonferroni correction; table 3). The magnitude of the fall in FEV1 slightly increased with increasing time intervals (table 3 ); this increase was statistically significant for absolute changes with both formoterol and terbutaline.

For terbutaline, formoterol and salmeterol, the AUC for the 5-min interval exercise test became positive 60-min after exercise, indicating that the bronchodilator effects and the recovery after exercise were superimposed (fig. 2a). Furthermore, terbutaline, formoterol and salmeterol showed a statistically significant $(p<0.01$, ANOVA) decrease in the AUC with increasing time between inhalation and exercise, but there were no differences between treatments.

\section{Discussion}

The present study compared the onset of protection against exercise-induced bronchoconstriction between the two long-acting $\beta_{2}$-agonists formoterol and salmeterol. Within 5-60 min after inhalation, protection, in terms of the absolute or per cent fall in FEV1, did not differ significantly between the two drugs and was similar to that of the short-acting $\beta_{2}$-agonist terbutaline. However, the onset of bronchodilation was different, that of formoterol being rapid, similar to terbutaline, and that of salmeterol being slow. With time, however, the bronchodilator effects became

Table 3.-Forced expiratory volume in one second $\left(F E V_{1}\right)$ after exercise for the three different time intervals between inhalation of the study drug and start of exercise

\begin{tabular}{|c|c|c|c|c|}
\hline & \multicolumn{3}{|c|}{ Time interval } & \multirow[t]{2}{*}{ p-value ${ }^{\#}$} \\
\hline & $5 \min$ & $30 \mathrm{~min}$ & $60 \mathrm{~min}$ & \\
\hline \multicolumn{5}{|c|}{ Maximum decrease in FEV1 \% } \\
\hline Placebo & $-22.0(-26.2--17.7)$ & $-22.4(-27.4-17.5)$ & $-25.1(-30.1--20.1)$ & NS \\
\hline Terbutaline & $-5.1(-8.6-1.6)$ & $-6.3(-9.4-3.2)$ & $-8.5(-11.8--5.1)$ & 0.09 \\
\hline Formoterol & $-1.8(-4.2-0.7)$ & $-5.7(-7.9-3.5)$ & $-5.6(-8.4-2.7)$ & 0.006 \\
\hline Salmeterol & $-5.9(-9.9-1.9)$ & $-7.6(-10.8--4.5)$ & $-7.0(-10.5--3.4)$ & NS \\
\hline \multicolumn{5}{|c|}{ Maximum decrease in FEV $1 \mathrm{~mL}$} \\
\hline Placebo & $-780(-959-601)$ & $-792(-969-614)$ & $-894(-1086-702)$ & NS \\
\hline Terbutaline & $-208(-335-82)$ & $-256(-365-146)$ & $-361(-506-216)$ & 0.034 \\
\hline Formoterol & $-89(-195-17)$ & $-233(-334-133)$ & $-243(-376-110)$ & 0.018 \\
\hline Salmeterol & $-242(-404-80)$ & $-296(-429-164)$ & $-276(-428-125)$ & NS \\
\hline
\end{tabular}

All data are presented as mean (95\% confidence interval) unless otherwise stated. ${ }^{\#}$ : analysis of variance between the three time intervals. 

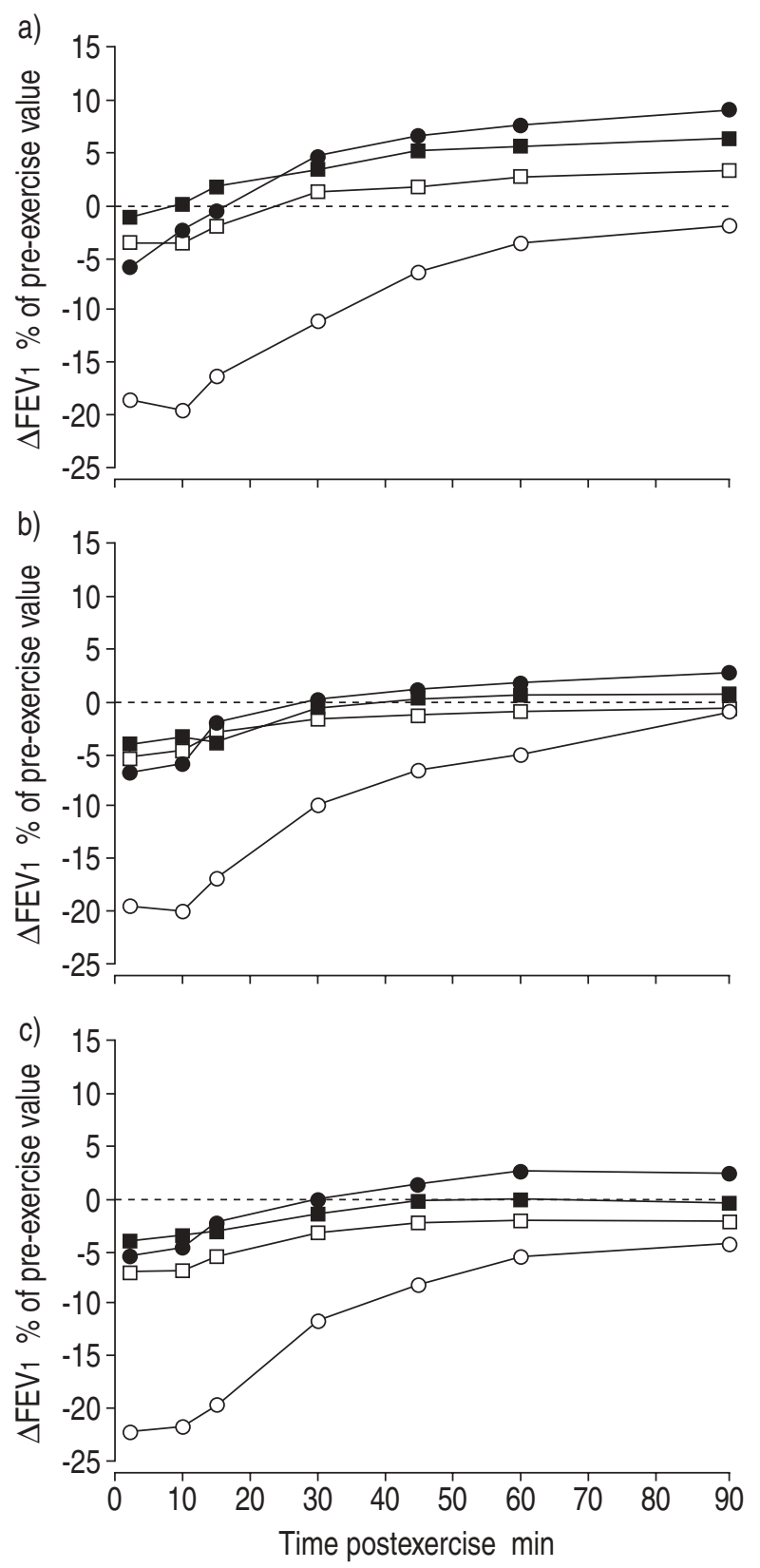

Fig. 2.-Change of forced expiratory volume in one second $(\mathrm{FEV} 1)$ after exercise expressed as $\%$ of the respective pre-exercise value for time intervals of a) $5 \mathrm{~min}$, b) $30 \mathrm{~min}$ and c) $60 \mathrm{~min}$ between inhalation of the study drug and start of exercise. Data are expressed as mean values. $\mathbf{\square}$ : formoterol; $\square$ : terbutaline; salmeterol; $\bigcirc$ : placebo.

comparable, indicating the equipotency of the doses chosen.

In the past, many studies have addressed the time course of bronchodilation, showing a rapid response to formoterol and a slower response to salmeterol; e.g. a $15 \%$ increase in FEV1 occurred 12-min after inhalation of $12 \mu \mathrm{g}$ formoterol and 31-min after $50 \mu \mathrm{g}$ salmeterol [7]. Protection against exercise-induced bronchoconstriction has not been studied in such detail, particularly for early time points such as 5 and $30 \mathrm{~min}$ as in the present study. The magnitude of protection found was within the values reported for formoterol $[5,6]$, salmeterol $[11,12]$ and terbutaline $[14,15]$ indicating that study conditions and subjects enrolled were similar to those of previous protocols. It also suggests that the observation of a similar protection for formoterol and salmeterol 5-30 min after inhalation fits with previous data using longer intervals of time.

The approach in this study required equipotent doses of drugs. The doses of $50 \mu \mathrm{g}$ dry-powder salmeterol via Diskus $\mathbb{R}$ and of $12 \mu \mathrm{g}$ dry-powder

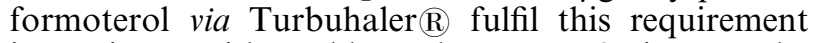
in patients with stable asthma [7]. Owing to the double-dummy design, terbutaline was included as a short-acting $\beta_{2}$-agonist available in dry-powder formulation, which was not the case for salbutamol. In terms of bronchodilation, $200 \mu \mathrm{g}$ salbutamol is equi-effective to $50 \mu \mathrm{g}$ salmeterol [16] and $250 \mu \mathrm{g}$ inhaled terbutaline is equivalent to $100 \mu \mathrm{g}$ salbutamol [17]. Thus it is likely that equipotent doses have been used. To keep the study manageable, different doses of the drugs were not included. It is possible that inhalation of lower or higher doses or different formulations would have changed the results. Although the dose-dependent effects of $\beta_{2}$-agonists are well known, the authors emphasize that the assumption of equipotent doses is supported a posteriori by the finding that effects became similar with time after inhalation. The number of subjects in this study was too small to obtain statistically valid results regarding the question of whether more severe exercise-induced bronchoconstriction was associated with a different outcome; additional trials at a higher ventilation rate or duration of exercise were not included.

The comparison of the time courses of bronchodilation and protection against exercise-induced bronchoconstriction raises two issues to be discussed. First, the classification of $\beta_{2}$-adrenoceptor agonists according to their onset of action cannot solely rely on bronchodilation, and secondly, it is independent from the duration of action. It has been proposed that $\beta_{2}$-agonists can be categorized as "fast"- versus "slow"acting in addition to "short"- versus "long"-acting [18], based on the observation that formoterol reversed methacholine-induced bronchoconstriction as rapidly as salbutamol and faster than salmeterol. These results cannot be expressed directly in terms of protection, but they are analogous to the conclusions derived from bronchodilator data [7]. The results of this study underline that there may be differential effects of bronchoprotection and bronchodilation. The difference between formoterol and salmeterol in the onset of action was significant for dilation but not for protection. Whether this phenomenon is limited to exercise-induced asthma or includes airway responsiveness to methacholine, histamine or adenosine monophosphate, is not clear, since the available data are difficult to compare with each other.

More specifically, this data suggests that the degree of protection against exercise-induced bronchoconstriction by $\beta_{2}$-agonists is not in parallel to the degree of bronchodilation achieved before the challenge, both with respect to the time course and the 
relationship between different types of $\beta_{2}$-agonists. This may be partly explained by the limited room for improvement in subjects with near-normal baseline lung function, partly by changes in baseline taken as a reference and partly by different mechanisms causing the responses (see later). Airway obstruction induced by exercise or cold-air hyperventilation is thought to be caused by mediators such as histamine [19] and leukotrienes [20, 21]. $\beta_{2}$-agonists can block the release of these mediators from mast cells [22, 23] and salmeterol can rapidly inhibit their release, as can salbutamol, despite the slower relaxation of airway smooth muscle [24]. This fact could have contributed to the finding that the time course of protection was comparable between terbutaline, formoterol and salmeterol.

Conversely, the time course of bronchodilation necessarily raises the question whether the results from this study were biased by the time schedule of the protocol or the changes in baseline values before exercise. Figure 3 illustrates the relationship between bronchodilation and bronchoconstriction in terms of FEV1 for each of the study drugs. It clearly shows that the exercise-induced airway response did not lead to a deterioration of FEV1 compared to baseline before inhalation of the study drug; bronchoconstriction was less than bronchodilation. The only condition where a slight fall in FEV1 occurred was the 5-min interval between salmeterol inhalation and start of exercise (fig. 3d). From these data it could be
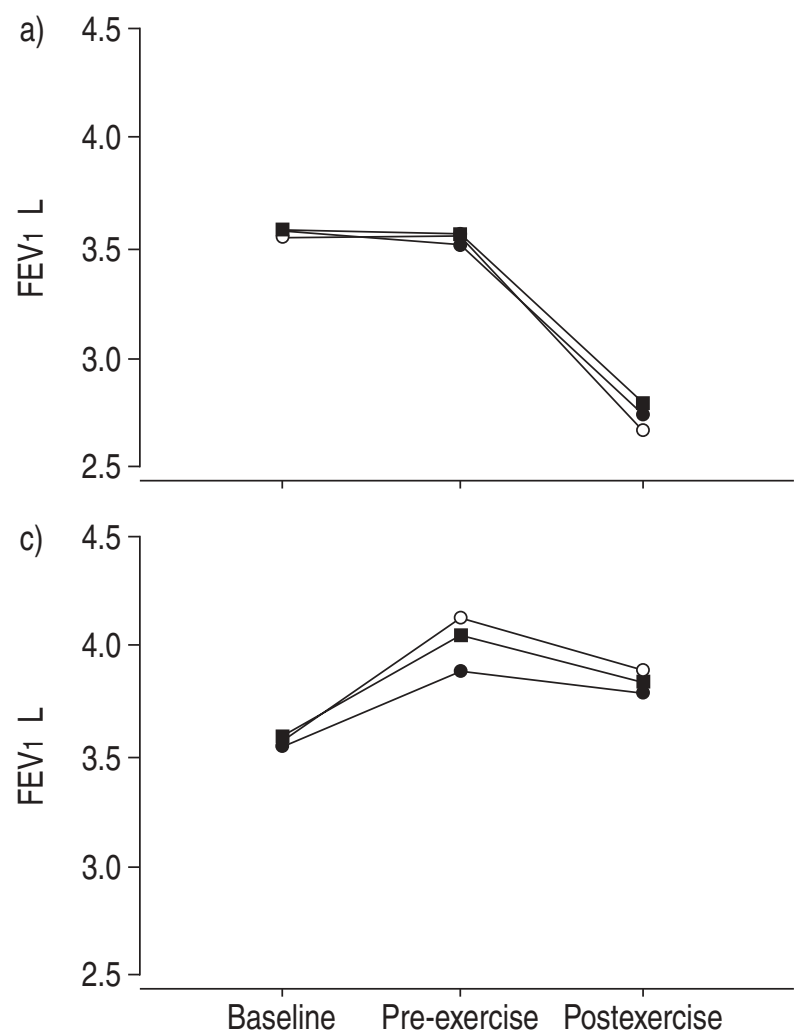

argued that both the onset of dilation and the onset of protection were slower with salmeterol compared to the other two drugs. However, when expressing the exercise-induced fall in FEV1 as either absolute or per cent changes relative to the pre-exercise value, as is common practice, responses were nearly parallel for the three time intervals between inhalation and start of exercise, particularly for salmeterol. This finding suggests that the apparent loss in protection in terms of the postexercise FEV1 was primarily due to incomplete bronchodilation, i.e. based on functional antagonism through airway smooth muscle relaxation.

Owing to the time needed for the exercise challenge, the first lung-function measurement after exercise was performed 14-min after inhalation of the study drug, when exercise actually started 5-min after inhalation. This time shift has also to be taken into account when comparing bronchodilation and bronchoconstriction. However, even when shifting the value taken for computing the fall in FEV1 from the 5-min value toward the 30-min value by approximately one-third of the distance (see pre-exercise values in fig. $3 \mathrm{~d}$ ), the magnitude of the fall in FEV1 remained similar between the three time intervals. In contrast, the magnitude of the bronchodilator response was clearly different and not affected by the shift in the time of measurement. This data supports the conclusion that the three drugs have a similar onset of protection but a dissimilar onset of

b)

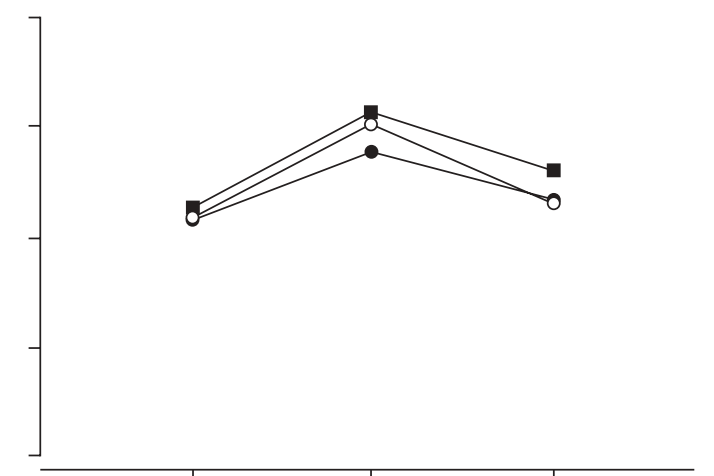

d)

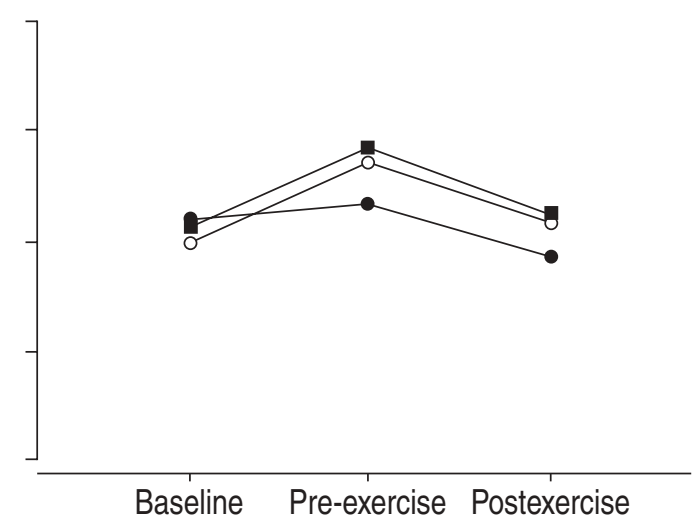

Fig. 3. - Comparison between bronchodilation and bronchoprotection showing absolute mean values of forced expiratory volume in one second (FEV1) at baseline, pre-exercise at $5(\mathbf{O}), 30(\mathbf{\square})$ or $60(\bigcirc)$ min after bronchodilator inhalation lowest and post-exercise value. a) placebo, b) terbutaline, c) formoterol and d) salmeterol. 
bronchodilation. It is also clear from figure 3 (a versus $\mathrm{b}-\mathrm{d}$ ), that all three drugs at all three times of inhalation were effective in protecting the subjects against exercise-induced bronchoconstriction, as compared to baseline. Thus they might be considered as clinically equivalent in achieving protection.

To conclude, the present study has demonstrated a rapid onset of protection against exercise-induced bronchoconstriction 5-60 min after inhalation, which was not significantly different between formoterol, salmeterol and terbutaline. In contrast, salmeterol showed delayed bronchodilation compared to terbutaline and formoterol as previously demonstrated. These findings imply that the two long-acting $\beta_{2}$-agonists tested are both capable of achieving acute, short-term protection against exercise-induced bronchoconstriction, and that this information might not be inferred from bronchodilator measurements.

\section{References}

1. British guidelines on asthma management. 1995 Review and position statement. Thorax 1997; 52: Suppl. 1, S1S21.

2. National Institute of Health. National Asthma Education and Prevention Program: Guidelines for the diagnosis and management of asthma. NIH Publication No. 97:4051A. 1997

3. Rabe KF, Jörres R, Nowak D, Behr N, Magnussen H. Comparison of the effects of salmeterol and formoterol on airway tone and responsiveness over 24 hours in bronchial asthma. Am Rev Respir Dis 1993; 147: 1436-1441.

4. Kemp JP, Dockhorn RJ, Busse WW, Bleecker ER, Van As A. Prolonged effect of inhaled salmeterol against exercise-induced bronchospasm. Am J Respir Crit Care Med 1994; 150: 1612-1615.

5. Patessio A, Podda A, Corone M, Trombetta N, Donner CF. Protective effect and duration of action of formoterol aerosol on exercise-induced asthma. Eur Respir J 1991; 4: 296-300.

6. McAlpine LG, Thomson NC. Prophylaxis of exerciseinduced asthma with inhaled formoterol, a long-acting beta 2-adrenergic agonist. Respir Med 1990; 84: 293295.

7. Palmqvist M, Persson G, Lazer L, Rosenborg J, Larsson, Lötvall J. Inhaled dry-powder formoterol and salmeterol in asthmatic patients: onset of action, duration of effect and potency. Eur Respir J 1997; 10: 2484-2489.

8. Rabe KF, Bodtke K, Liebig S, Magnussen $\mathrm{H}$. Modulation of inherent tone of human airways in vitro. Am Rev Respir Dis 1992; 145: A378.

9. Magnussen H, Reuss G, Jörres R. Methylxanthines inhibit exercise-induced bronchoconstriction at low serum theophylline concentration and in a dosedependent fashion. J Allergy Clin Immunol 1988; 81: 531-537.
10. Nielsen KG, Skov M, Klug B, Ifversen M, Bisgaard $\mathrm{H}$. Flow-dependent effect of formoterol dry-powder inhaled from the Aerolizer. Eur Respir J 1997; 10: 2105-2109.

11. Anderson SD, Rodwell LT, Du Toit J, Young ICH. Duration of protection by inhaled salmeterol in exercise-induced asthma. Chest 1991; 100: 1254-1260.

12. de Benedictis FM, Tuteri G, Pazzelli P, Niccoli A, Mezzetti D, Vaccaro R. Salmeterol in exercise-induced bronchoconstriction in asthmatic children: comparison of two doses. Eur Respir J 1996; 9: 2099-2103.

13. Standardization of Spirometry 1994 Update. American Thoracic Society. Am J Respir Crit Care Med 1995; 152: 1107-1136.

14. Anderson S, Seale JP, Ferris L, Schoeffel R, Lindsay DA. An evaluation of pharmacotherapy for exerciseinduced asthma. J Allergy Clin Immunol 1979; 64: 612624.

15. O'Byrne PM, Morris M, Roberts R, Hargreave FE. Inhibition of the bronchial response to respiratory heat exchange by increasing doses of terbutaline sulphate. Thorax 1982; 37: 913-917.

16. van Noord JA, Smeets JJ, Raaijmakers JA, Bommer AM, Maesen FP. Salmeterol versus formoterol in patients with moderately severe asthma: onset and duration of action. Eur Respir J 1996; 9: 1684-1688.

17. Freedman BJ. Trial of a terbutaline aerosol in the treatment of asthma and a comparison of its effects with those of a salbutamol aerosol. Br J Dis Chest 1972; 66: 222-229.

18. Politiek MJ, Boorsma M, Aalbers R. Comparison of formoterol, salbutamol and salmeterol in methacholine-induced severe bronchoconstriction. Eur Respir $J$ 1999; 13: 988-992.

19. Pliss LB, Ingenito EP, Ingram RH, Pichurko $B$. Assessment of bronchoalveolar cell and mediator response to isocapnic hyperpnea in asthma. Am Rev Respir Dis 1990; 142: 73-78.

20. Kikawa $\mathrm{Y}$, Miyanomae $\mathrm{T}$, Inoue $\mathrm{Y}$, et al. Urinary leukotriene $\mathrm{E}_{4}$ after exercise challenge in children with asthma. J Allergy Clin Immunol 1992; 89: 11111119.

21. Finnerty JP, Wood-Baker R, Thomson H, Holgate ST. Role of leukotrienes in exercise-induced asthma. Inhibitory effect of ICI 204,219, a potent leukotriene D4 antagonist. Am Rev Respir Dis 1992; 145: 746-749.

22. Nials AT, Ball DI, Butchers PR, et al. Formoterol on airway smooth muscle and human lung mast cells: a comparison with salbutamol and salmeterol. Eur J Pharmacol 1994; 251: 127-135.

23. Peters SP, Schulman ES, Schleimer RP, MacGlashan DW, Newball HH, Lichstein LM. Dispersed human lung mast cells. Pharmacologic aspects and comparison with human lung tissue fragments. Am Rev Respir Dis 1982; 126: 1034-1039.

24. Butchers PR, Vardey CJ, Johnson M. Salmeterol: a potent and long-acting inhibitor of inflammatory mediator release from human lung. Br J Pharmacol 1991; 104: 672-676. 